\title{
Huntington's chorea and tryptophan
}

\author{
W. R. MCLEOD AND D. J. DE L. HORNE \\ From the Department of Psychiatry, School of Medicine, \\ University of Melbourne, Parkville, Victoria, Australia
}

SUMMARY Daily use of $7 \mathrm{~g}$ L-tryptophan and $70 \mathrm{mg}$ pyridoxine for 14 days led to no deteriorationס of objectively measured manual motor skills in a small group of patients with Huntington's chorea.

Reports previously published suggest that serotonin metabolites are associated with the pathogenesis of chorea (Faurbye, 1970; Klawans, 1970), but their precise role is yet to be established.

Conflicting reports have followed experiments using daily doses of tryptophan given orally. Oepen and Oepen (1969) found no deterioration in the motor performance of patients with Huntington's chorea given $10 \mathrm{~g}$ of L-tryptophan daily, while smaller doses given by Barbeau produced choreiform movements in patients with juvenile Huntington's disease and in other choreiform patients (Barbeau, 1969). Another serotonin precursor, 5-hydroxy-tryptophan, given orally was said to aggravate the severity of choreiform movements in patients with Huntington's chorea (Lee, Markham, and Clark, 1967). Oliphant, Evans, and Forrest using both tryptophan and 5-hydroxy tryptophan found no increase in abnormal movements. (Oliphant, Evans, and Forrest, 1960).

In experimental animals choreiform movements can be produced by lesions to the serotoninergic pathways which originate in the dorsal and median raphe nuclei of the mesencephalon and ascend, in association with the medial forebrain bundle, to the corpus striatum, hypothalamus, thalamus and limbic system (Poirier and Sourkes, 1965; Aghajanian, Bloom, and Sheard, 1969). Subsequently, the concentration of serotonin is decreased in the corpus striatum (Faurbye, 1970). As a similar deficit of serotonin is found in the brain of patients with Huntington's chorea (Klawans, 1970), oral tryptophan would not be expected to increase the abnormal movements.

This paper reports the use of oral tryptophan given to a small group of such patients and the objective measures used to assess changes inos certain motor skills.

\section{SUBJECTS}

Four patients were chosen with Huntington's chorea; all had marked choreiform movements. $\dot{\omega}$ They were matched, with respect to age and sex, with? four normal volunteer subjects included to detep-ir mine the effects of practice on the performance क्षf the tasks. The control subjects received no medicg tion.

Each patient was given $7 \mathrm{~g}$ per day of L-tryptoph角 in divided doses for a total of 14 days. In additionc each patient received $70 \mathrm{mg}$ pyridoxine per day.

\section{TEST PROCEDURES}

To assess manual dexterity a bead and tapping test and a letter cancellation test were performed at the commencement and at the end of the trial by both $\bar{\partial}$ the patients and the controls and their performance recorded. Both tests used were devised by Talland $\underset{\Omega}{\mathbb{Q}}$ and Schwab (1964).

1. LETTER CANCELLATION TEST This test consisted of a page of random letters with lines of 36 letters, each? line containing a random allocation of 10 capitals and four double spacings between letters. The subject was required to cancel only the capital letters as:quickly as possible and not to stop to correct any mistakes made.

The scores used were the average number per minute of letters correctly cancelled (from two trials $\mathrm{O}$ of 60 seconds per subject) and the total number of letters covered from the start of the page to the lasto cancellation mark.

2. BEAD AND TAPPER TEST In this test two com- $N$ ponent tasks were involved. One was to transfer beads, using a pair of tweezers, from a full cup to ano empty one. Each subject used his preferred hand 
which in all cases but one (a patient with Huntington's chorea) was the right.

The second task was to tap a morse tapper as quickly as possible with the non-preferred hand (the left one except for the one patient mentioned).

A standard practice session was given before commencement of the experimental trials. There were two 60 second trials of each task combination: beads alone, tapping alone, beads and tapping simultaneously-with a change of hands when this task was repeated for the second time. Scores were the number of taps (recorded electrically) and the number of beads transferred into the empty pot and were the average of the two trials.

\section{RESULTS}

The change in the average score for all tasks from occasion 1 to occasion 2 was used as a measure of improvement. There was no significant difference between the control and the Huntington's disease group. The two groups, however, are not strictly comparable, for the initial scores of the control groups are much higher than those of the Huntington's disease group, although the improvement with practice is similar in both groups (see Table). Carroll, Mowbray, and Davies (1970) used identical tablets of L-tryptophan and pyridoxine (each $0.5 \mathrm{~g}$ tablet of tryptophan containing $5 \mathrm{mg}$ pyridoxine). In their study the group receiving L-tryptophan consisted of severely depressed patients. No patient developed abnormal movements. However, a disturbance of brain indoleamine metabolism has been found in some severely depressed patients and hence they cannot serve as a well-matched control group. In further studies a placebo group could be matched with the active drug group, with persons affected with the disease. The important finding in this study however, is that no person was made worse by tryptophan. Indeed, one patient, a male aged 26 years showed tremendous improvement in the use of his left hand in the second testing.

\section{COMMENT}

The findings reported here do not support the observations of Barbeau (1969) who used only $1 \mathrm{~g}$ L-tryptophan daily, in a single patient, and reported that choreiform movements were increased.

The results do support the findings of Oepen and Oepen (1969) who found no deterioration of behaviour or aggravation of abnormal movements when using $10 \mathrm{~g}$ L-tryptophan per day. Pyridoxine alone does not appear to aggravate choreiform movements (Paulson, 1971) and was included to ensure that some of the digested L-tryptophan became serotonin, since it is known that a diet poor in pyridoxine reduces considerably the serotonin levels in many tissues (Garattini and Valzelli, 1965).

Morris, Prange, Hall, and Weiss (1971) investigating benign tremor gave a dose of L-tryptophan daily for seven days which gradually increased to a daily dose of $6 \mathrm{~g}$. This dose

TABLE

CHANGE OF SCORE (OCCASION 2 MINUS OCCASION 1) FOR MANUAL DEXTERITY TESTS

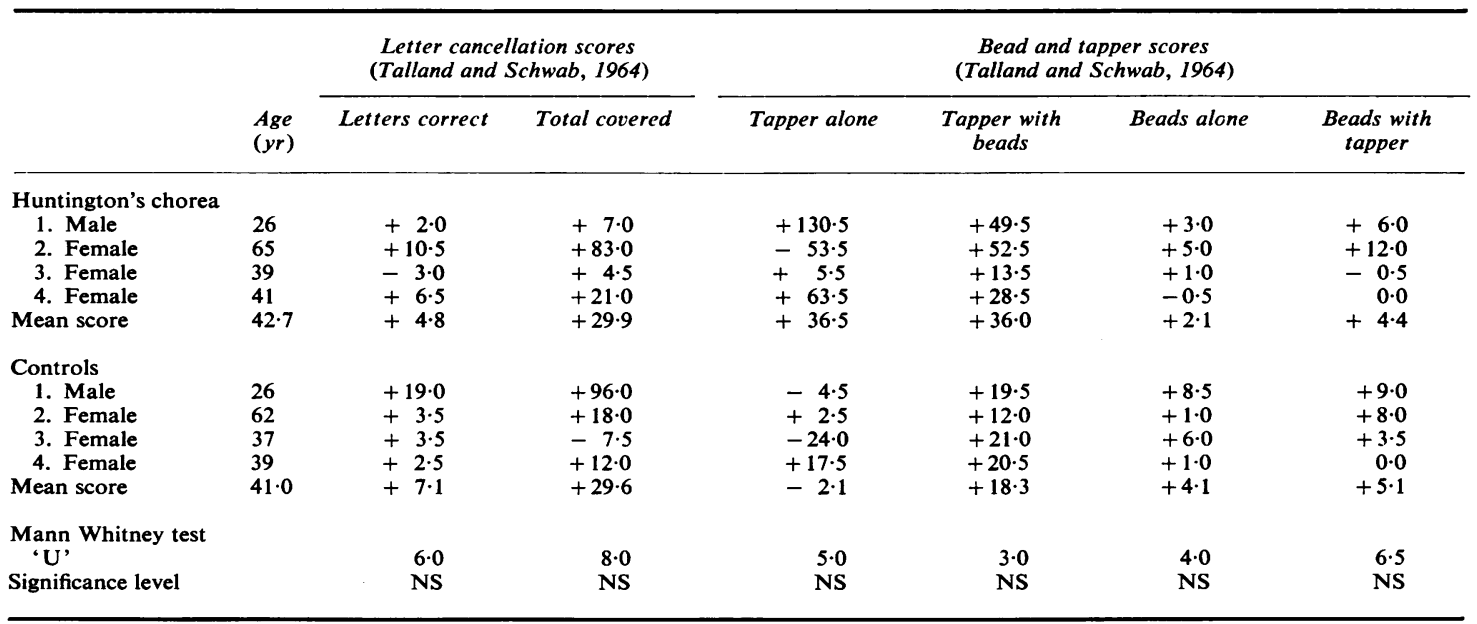

Plus sign denotes improvement and minus sign decrement in performance on occasion 2. 
was then maintained for a further seven days after which a daily dose of $50 \mathrm{mg}$ pyridoxine was added for another 14 days. No change in the tremor was reported in either of two patients.

It would appear that large daily doses of tryptophan, or tryptophan and pyridoxine, or pyridoxine alone do not aggravate choreiform movements in patients with Huntington's chorea. These results do not agree with those of Barbeau (1969), and are difficult to reconcile with those of Lee et al. (1967).

Huntington's chorea is a progressive degenerative disease of the brain which is inherited as an autosomal dominant gene with complete penetrance (Bruyn, 1968). Bruyn argued that Huntington's chorea in certain respects seemed to be the opposite of Parkinson's disease, particularly with reference to the nigrostriatal system. This argument must not be taken too far, for the lesion in Parkinson's disease is predominantly in the substantia nigra within which the normally dopamine-rich cells show marked degenerative changes. In Huntington's chorea the distribution of pathological changes is quite different, for the dopamine cells of the substantia nigra are not basically affected, although there is a loss of nerve cells in the putamen and the caudate nucleus as well as in the cortex and other parts of the brain. Lesions in the subthalamic nucleus produce choreiform movements in monkeys (Faurbye, 1970). Poirier and Sourkes (1965) provoked choreiform and ballistic movements in monkeys by lesions in the mesencephalon of two neurone systems simultaneously, the serotonin pathways to the striatal complex and the rubrotectal spinal tract; the dopaminergic nigrostriatal pathways remained intact. Therapeutic experiments reported by Faurbye suggest the same pathogenesis for choreiform movements in Huntington's chorea (Faurbye, 1970).

The malfunction of the extrapyramidal system in Huntington's chorea may be due to disturbance of the balance between the excitatory compounds, acetylcholine and histamine (Barbeau, 1962) and serotonin and catecholamines, possibly inhibitory substances (Smythies, 1965). The administration of L-dopa in Parkinson's disease may be associated with the production of choreiform movements as a side-effect, and the imbalance between these compounds, actual or relative, may be important aetiological factors.
Disturbances of dopamine metabolism have not been detected in cases of Huntington's $Z$ chorea and Lee et al. (1967) and Barbeau (1969) have argued for the role of serotonin in the disorder. McNamee, Kelvin, and Turnbull (1971) have shown a urinary excretion of 5-hydroxy- 0 indoleacetic acid higher in a group of Hunting ton's patients than in a group of control sub-ड jects, and suggest that this lends support to Lee et al. The group of control subjects used, however, were hospitalized patients and both a nonhospitalized group and the Huntington's chorea? group of patients showed similar levels.

Klawans, Ilahi, and Shenker (1970) believe $\frac{\overline{\bar{\rho}}}{\frac{D}{\sigma}}$ that the lesion of Huntington's chorea is such that the striatal cells become abnormally sensi-ळ tive to the normal release of neurotransmitters. 0 They state "it is clear that giving patients with: Huntington's chorea the precursors of the puta- $\vec{\omega}$ tive neurotransmitter increases the involuntary movements'. With respect to tryptophan, ouro observations do not support this assertion.

\section{REFERENCES}

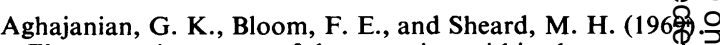
Electron microscopy of degeneration within the serotorion_pathway of rat brain. Brain Research, 13, 266-273.

Barbeau, A. (1962). The pathogenesis of Parkinson's diseaş a new hypothesis. Canadian Medical Association Journe 87, 802-807.

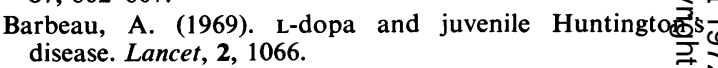

Bruyn, G. W. (1968). Huntington's chorea. Historical, clinical and laboratory synopsis. In Handbook of Clinical Neurology. Diseases of the Basal Ganglia. Edited by P. J. 오 Vinken and G. W. Bryn, 6, 298-378. North-Holland: Amsterdam.

Carroll, B. J., Mowbray, R. M., and Davies, B. (1970). Sequential comparison of L-tryptophan with E.C.T. in severe depression. Lancet, 1, 967-969.

Faurbye, A. (1970). The structural and biochemical basis of $\overline{\bar{O}}$ movement disorders in treatment with neuroleptic drugs 3

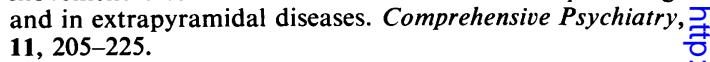

Garattini, S., and Valzelli, L. (1965). Serotonin. Elsevier:Amsterdam.

Klawans, H. L., Jr. (1970). A pharmacologic analysis of Huntington's chorea. European Neurology, 4, 148-163.

Klawans, H., Jr., Ilahi, M. M., and Shenker, D. (1970). 글 Theoretical implications of the use of L-dopa in Parkinson-? ism. A review. Acta Neurologica Scandinavica, 46, 409-441. 윽

Lee, D. K., Markham, C. H., and Clark, W. G. (1967). Serotonin (5-hydroxytryptamine) metabolism in Hunting-을 ton's chorea (abstract). Excerpta Medica International Congress Series No. 154, 41-42. Excerpta Medica:을. Amsterdam.

McNamee, B., Kelvin, A. S., and Turnbull, M. J. (1971). N Urinary excretion of some monoamines and metabolites in Huntington's chorea. Scottish Medical Journal, 16, 247- N 249.

Morris, C. E., Prange, A. J., Jr., Hall, C. D., and Weiss, E. A. (1971). Inefficiency of tryptophan pyridoxine in essential tremor. Lancet, 2, 165-166. 
Oepen, I., and Oepen, H. (1969). Tryptophanbelastungstest bei Huntingtonscher Chorea. Humangenetik, 7, 197-202.

Oliphant, J., Evans, J. I., and Forrest, A. D. (1960). Huntington's chorea-some biochemical and therapeutic aspects. Journal of Mental Science, 106, 718-725.

Paulson, G. W. (1971). Use of pyridoyine in chorea. American Journal of Psychiatry, 127, 1091-1092.

Poirier, L. J., and Sourkes, T. L. (1965). Influence of the substantia nigra on the catecholamine content of the striatum. Brain, 88, 181-192.

Smythies, J. R. (1965). Psychiatric and biochemical aspects of Parkinsonism. Journal of Psychosomatic Research, 9, 103-109.

Talland, G. A., and Schwab, R. S. (1964). Performance with multiple sets in Parkinson's disease. Neuropsychologia, 2 45-53. 